\title{
Multimorbidity in older adults: magnitude and challenges for the Brazilian health system
}

\author{
Bruno Pereira Nunes ${ }^{1,2^{*}}$, Elaine Thumé ${ }^{1,3}$ and Luiz Augusto Facchini ${ }^{2,3}$
}

\begin{abstract}
Background: Multimorbidity is a public health problem with high prevalence and important consequences. The aim of this paper was to verify the prevalence and distribution of multimorbidity in Brazilian older adults.

Methods: A population-based survey was carried out in 2008 through face-to-face interviews with 1593 older adults (aged 60 or over) living in Bagé, a medium-sized city in Southern Brazil. Multimorbidity was evaluated by 17 morbidities and operationalized according to two cutoff points: 2 or more and 3 or more morbidities. Descriptive analysis examined the occurrence of multimorbidity by demographic, socioeconomic and health services variables. Observed and expected dyads and triads of diseases were calculated.

Results: From total sample, $6 \%$ did not have morbidities. Mean morbidity was 3.6. Morbidities showing higher prevalence were high blood pressure - HBP - $(55.3 \%)$ and spinal column disease (37.4\%). The percent of participants with multimorbidity was $81.3 \%$ (95 \% Cl: 79.3; 83.3) for 2 or more morbidities and $64.0 \%$ (95 \% Cl: 61.5; 66.4) for 3 or more morbidities. In both measures occurrence was higher among women, the more elderly, less socioeconomic status, the bedridden, those who did not have a health private plan, those who used health services and those living in Family Health Strategy catchment areas. We found 22 dyads of morbidities with prevalence $10 \%$ or more and 35 triads with prevalence $5 \%$ or more. The most prevalent observed pair and triplet of morbidities were HBP and spinal column disease (23.6 \%) and HBP, rheumatism/arthritis/arthrosis and spinal column disease $(10.6 \%)$, respectively.
\end{abstract}

Conclusions: Multimorbidity frequency was high in the sample studied, in keeping with percentage found in other countries. The social inequities identified increase the health system challenges for the management of multimorbidity, requiring a comprehensive and multidimensional care. The combinations of diseases can provide initial input to include multimorbidity in Brazilian clinical protocols.

Keywords: Comorbidity, Multimorbidity, Chronic diseases, Aged, Elderly, Cross-sectional studies, Brazil

\section{Background}

Multimorbidity is the occurrence of multiple health problems in the same individual [1]. Its concept and operationalization have been increasingly discussed $[2,3]$ due to the rise - absolute and relative - in noncommunicable chronic diseases $(\mathrm{NCD})$ and health expectancy of the world's population $[4,5]$.

\footnotetext{
* Correspondence: nunesbp@gmail.com

${ }^{1}$ Department of Nursing, Federal University of Pelotas, Rua Gomes Carneiro, 1, 96010-610 Pelotas, RS, Brazil

${ }^{2}$ Department of Social Medicine, Postgraduate Program of Epidemiology, Federal University of Pelotas, Pelotas, Brazil

Full list of author information is available at the end of the article
}

Multimorbidity is a public health problem in terms of its prevalence, severity and possibility of control [6]. The occurrence of various health problems in older adults is high $(>50 \%)[1]$ and the consequences may include increased risk of death and functional decline [7], besides having a negative impact on the quality of life and life expectancy [8].

In Brazil, despite the problem's relevance, resulting from accelerated demographic and epidemiologic transition, studies about multimorbidity are scarce. The few studies identified addressed women aged 40 to 65 with 11 or 
more years of schooling [9], women $\geq 50$ years old [10] and adults $\geq 18$ years old as their target population [11].

Although multimorbidity is possible to control, an adequate approach to its management is a challenge for health systems and services worldwide [12]. In Brazil, the Unified Health System (Sistema Único de Saúde SUS) and the Family Health Strategy (FHS) (Estratégia Saúde da Família) have made important progress in health service coverage and use, including the poorest and most vulnerable populations [13-15].

The FHS is the organizational axis of primary health care (PHC) in Brazil [16]. It is based on a multidisciplinary team working with a defined population and territory and has the potential to identify and monitor elderly people with NCDs and multimorbidity. However, to increases its effectiveness, FHS should improve multidimensional assessment of the elderly, in order to establish complex care plans, including prevention and health promotion, thus guiding the organization and the provision of health services [17-19].

Knowing the magnitude of multimorbidity can contribute to the organization of services, health worker training and the elaboration and improvement of clinical guidelines, facilitating the proper management of the health of the elderly, preventing avoidable hospitalizations and iatrogenesis in the treatment of morbidities $[17,19]$. This study therefore aims to measure the prevalence of multimorbidity and its association with demographic, socioeconomic and health care variables in the elderly population. Observed and expected dyads and triads of diseases were also estimated.

\section{Methods}

A population-based cross-sectional study was performed using data collected between July and November 2008 on individuals aged 60 or older, resident in the primary health care service catchment area of the urban zone of the municipality of Bagé-RS, located on the southern border of Rio do Grande do Sul state with Uruguay. In 2008 Bagé had some 120,000 inhabitants (84 \% in the urban zone). The Family Health Strategy (FHS) had been implanted for five years and covered $51.0 \%$ of the urban population. The rest of the population was covered by the traditional health care model. The elderly accounted for approximately $14 \%$ of the population.

The sample size was calculated for a larger study [20, 21]. Considering $10 \%$ for losses and refusals, as well as a design effect of 1.3, the study had $80 \%$ statistical power to detect relative risks of 1.5 and exposures affecting at least $4 \%$ of population.

When delimiting the sample, the catchment area of each of the PHC centers was defined and later divided into micro-areas, with each block of buildings being numerically identified. To guarantee equiprobability at the household level, the starting point for data collection in each of the blocks was selected randomly. One in every six households were visited. No replacements were admitted. All residents of these households aged 60 or older were invited to take part in the study. Interviews not conducted after three attempts on different days and times were considered to be losses/refusals. The probability of locating an elderly household member was estimated at 1 in every 3 households. This estimate ensure a widespread distribution of the sample given the proportion of elderly individuals in the general population $(8-10 \%)$.

Data collection was done by 15 interviewers coordinated by three trained supervisors. Training included theoretical explanations about the questionnaire using an instruction manual, conducting interviews, practical training in field work logistics and meetings during the data collection stage. The interviews were conducted using structured questionnaires with pre-coded questions applied to all the elderly in the households selected. In cases of partial incapacity - elderly people with lucid and focused communication ability but needing everyday accompaniment -, family members and main carers provided the answers. Questions requiring self-reported answers were not applied in cases of total incapacity - elderly people unable to communicate and with complete dependence on family members and/or carers.

The outcome was multimorbidity measured according to the health problems presented in Table 1. Multimorbidity was operationalized through diseases count, and combining the diseases according to two cutoff points suggested in the literature: a. $\geq 2$ morbidities; and b. $\geq 3$ morbidities [1, 22, 23].

The demographic, socioeconomic and health services variables included were: sex (male/female); self-reported skin color (white/black/yellow, brown or indigenous); age (60-64/65-69/70-74/ $\geq 75$ years old); marital status (married or living with a stable partner/widow(er)/divorced or never married); years of schooling (none/1-7/ 28); economic class as per the Associação Brasileira de Empresas de Pesquisas (ABEP) (A and $\mathrm{B}$ - richer/C/D and $E$ - poorer); bedridden in the month prior to the interview (no/yes); private health plan (no/yes); medical visit in the 3 months prior to the interview (no/yes); emergency services visit in the 3 months prior to the interview (no/yes); hospitalization in the twelve months prior to the interview (no/yes); and type of primary care center (traditional/FHS).

The proportions and their respective $95 \%$ confidence intervals were calculated. The mean, median and interquartile range (Q25-Q75) were measured for the length of time the person had had the disease (diseases with medical diagnosis and amputation) and the number of 
Table 1 Health problems used to operationalize multimorbidity

\begin{tabular}{|c|c|c|c|}
\hline Morbidity & How information was gathered? & Question or scale & Case \\
\hline 1) High Blood Pressure (HBP) & $\begin{array}{l}\text { Medical diagnosis } \\
\text { self-reported }\end{array}$ & Has a physician told you that you have High Blood Pressure? & Yes \\
\hline 2) Diabetes & $\begin{array}{l}\text { Medical diagnosis } \\
\text { self-reported }\end{array}$ & $\begin{array}{l}\text { Has a physician told you that you have diabetes or high blood } \\
\text { sugar levels? }\end{array}$ & Yes \\
\hline 3) Lung problem & $\begin{array}{l}\text { Medical diagnosis } \\
\text { self-reported }\end{array}$ & $\begin{array}{l}\text { Has a physician told you that you have lung problem } \\
\text { (bronchitis, emphysema, COPD, asthma)? }\end{array}$ & Yes \\
\hline 4) Heart problem & $\begin{array}{l}\text { Medical diagnosis } \\
\text { self-reported }\end{array}$ & Has a physician told you that you have heart problem? & Yes \\
\hline 5) Stroke & $\begin{array}{l}\text { Medical diagnosis } \\
\text { self-reported }\end{array}$ & Has a physician told you that you have had stroke? & Yes \\
\hline 6) Rheumatism, arthritis or arthrosis & $\begin{array}{l}\text { Medical diagnosis } \\
\text { self-reported }\end{array}$ & $\begin{array}{l}\text { Has a physician told you that you have rheumatism, arthritis } \\
\text { or arthrosis? }\end{array}$ & Yes \\
\hline $\begin{array}{l}\text { 7) Disease in spinal column } \\
\text { (any problem reported) }\end{array}$ & $\begin{array}{l}\text { Medical diagnosis } \\
\text { self-reported }\end{array}$ & $\begin{array}{l}\text { Has a physician told you that you have a disease in your } \\
\text { spinal column? }\end{array}$ & Yes \\
\hline 8) Cancer & $\begin{array}{l}\text { Medical diagnosis } \\
\text { self-reported }\end{array}$ & Has a physician ever told you that you had cancer? & Yes \\
\hline 9) Kidney problem & $\begin{array}{l}\text { Medical diagnosis } \\
\text { self-reported }\end{array}$ & Has a physician told you that you have a kidney problem? & Yes \\
\hline 10) Cognitive impairment & Scale & Mini-Mental State Examination (MMSE), composed of 30 items $[46,47]$ & $\leq 22$ \\
\hline 11) Depression & Scale & Geriatric Depression Scale (GDS), composed of 15 items [48] & $\geq 6$ \\
\hline 12) Urinary incontinence & Self-reported & Do you have problem of accidentally wetting yourself? & Yes \\
\hline $\begin{array}{l}\text { 13) Amputation in any part } \\
\text { of the body }\end{array}$ & Self-reported & At any time in life have you had to amputate some part of your body? & Yes \\
\hline 14) Eyesight problem & Self-reported & $\begin{array}{l}\text { Does your eyesight hinder you in doing the things you need or want } \\
\text { to do? }\end{array}$ & Yes \\
\hline 15) Hearing problem & Self-reported & $\begin{array}{l}\text { Does your hearing hinder you in doing the activities that you need or } \\
\text { want to do? }\end{array}$ & Yes \\
\hline 16) Problem chewing food & Self-reported & Do you have any problem or difficulty chewing food? & Yes \\
\hline 17) Falls & Self-reported & Have you fallen at any time since $<1$ year ago $>$ until now? & Yes \\
\hline
\end{tabular}

diseases. In addition a projection of observed prevalence was made in order to estimate the absolute number of elderly people living in Bagé city with a given morbidity or multimorbidity. As such, the prevalence found was extrapolated to include all elderly people living in the urban area of the municipality of Bagé-RS in 2010 based on information available in the 2010 census conducted by the Brazilian Institute of Geography and Statistics (IBGE) (available at: http://cod.ibge.gov.br/6e6j).

The prevalence of dyads ( $\geq 10 \%)$ and triads ( $\geq 5 \%$ ) of health problems was measured. The ratios (and respective $95 \%$ confidence intervals) between observed and expected frequency were calculated to measure any occurrence of dyads and triads beyond expected frequency by chance [24]. The expected frequencies were calculated by multiplying individual prevalence of the diseases. Data analysis was performed using Stata version 12 .

The project was approved by the Research Ethics Committee of the Federal University of Pelotas (Protocol No. 015/2008). Ethical principles were ensured using a Voluntary Informed Consent form signed by the respondents or those responsible for them. The right not to participate in the study and the anonymity of the respondents was guaranteed. The authors declared that they had no conflict of interest in this study.

\section{Results}

We identified 1593 elderly household members. Losses represented $4.0 \%$ and refusals, $3.0 \%$. Almost two thirds were women $(62.8 \%)$. The most reported skin color was white $(78.6 \%)$. Elderly people between 60 and 64 years old accounted for $25.1 \%$ and those aged $\geq 75$ accounted for $31.2 \%$ of those interviewed. More than half (51.2\%) were married or lived with partner and $33.8 \%$ were widowed. The majority of the elderly had between 1 and 7 years of schooling and $23.7 \%$ had not attended school. Economic classes D/E and C accounted for 34.0 and $38.9 \%$, respectively. The bedridden represented $9.3 \%$ of the sample. Two-thirds $(35.4 \%)$ have private health plan. More than a half (54.6\%) had a medical visit, $12.8 \%$ visited emergency services and $17.7 \%$ were hospitalized. The living in FHS catchment areas covered $53.5 \%$ of the elderly (Table 2). 
Table 2 Sample description and prevalence of multimorbidity according demographic, socioeconomic and health services characteristics

\begin{tabular}{|c|c|c|c|c|c|c|}
\hline \multirow[t]{2}{*}{ Variables } & \multicolumn{2}{|c|}{ Sample } & \multicolumn{4}{|l|}{ Multimorbidity } \\
\hline & $n$ & $\%$ & $\geq 2 \%(95 \% \mathrm{Cl})$ & $\begin{array}{l}\text { No. of cases in } \\
\text { target population }\end{array}$ & $\geq 3 \%(95 \% \mathrm{Cl})$ & $\begin{array}{l}\text { No. of cases in } \\
\text { target population }\end{array}$ \\
\hline \multicolumn{7}{|l|}{ Sex } \\
\hline Male & 593 & 37.2 & $67.3(63.4 ; 71.3)$ & 3795 & $45.9(41.7 ; 50.1)$ & 2589 \\
\hline Female & 1000 & 62.8 & $82.1(80.0 ; 84.6)$ & 7816 & $65.3(62.3 ; 68.4)$ & 6217 \\
\hline \multicolumn{7}{|l|}{ Skin color } \\
\hline White & 1252 & 78.6 & $74.7(72.2 ; 77.2)$ & 8901 & $55.1(52.2 ; 57.9)$ & 6566 \\
\hline Black & 139 & 8.7 & $79.8(72.7 ;$ 86.9) & 1052 & $68.5(60.3 ; 76.8)$ & 903 \\
\hline Brown/yellow/indigenous & 202 & 12.7 & $86.2(81.3 ; 91.2)$ & 1660 & $70.4(63.8 ; 76.9)$ & 1355 \\
\hline \multicolumn{7}{|l|}{ Age } \\
\hline $60-64$ & 400 & 25.1 & $72.4(68.0 ; 77.0)$ & 2755 & $52.0(46.9 ; 57.0)$ & 1979 \\
\hline $65-69$ & 374 & 23.5 & $72.1(67.5 ; 76.8)$ & 2569 & $55.4(50.3 ; 60.6)$ & 1974 \\
\hline $70-74$ & 322 & 20.2 & $77.7(73.0 ; 82.5)$ & 2379 & $57.8(52.2 ; 63.4)$ & 1770 \\
\hline$\geq 75$ & 497 & 31.2 & $83.3(79.8 ; 86.8)$ & 3940 & $66.1(61.6 ; 70.5)$ & 3126 \\
\hline \multicolumn{7}{|l|}{ Years of schooling } \\
\hline None & 372 & 23.7 & $87.1(83.5 ; 90,7)$ & 3129 & $72.1(67.4 ; 76.9)$ & 2590 \\
\hline $1-7$ & 858 & 54.5 & 76.9 (74.0; 79.9) & 6354 & $57.3(53.8 ; 60.7)$ & 4734 \\
\hline$\geq 8$ & 342 & 21.8 & $64.8(59.5 ; 70.0)$ & 2142 & $45.3(39.8 ; 50.8)$ & 1497 \\
\hline \multicolumn{7}{|l|}{ Economic class (ABEP) } \\
\hline$A$ and $B$ (richer) & 429 & 27.1 & $69.1(64.6 ; 73.7)$ & 2839 & $51.3(46.3 ; 56.2)$ & 2108 \\
\hline C & 615 & 38.9 & $75.1(71.6 ; 78.7)$ & 4429 & $55.7(51.6 ; 59.8)$ & 3285 \\
\hline$D$ and $E$ & 537 & 34.0 & $84.0(80.8 ; 87.2)$ & 4330 & $66.1(62.0 ; 70.3)$ & 3407 \\
\hline \multicolumn{7}{|l|}{ Bedridden } \\
\hline No & 1445 & 90.7 & $80.3(78.1 ; 82.4)$ & 11041 & $61.9(59.4 ; 64.5)$ & 8511 \\
\hline Yes & 148 & 9.3 & $92.7(88.1 ; 97.3)$ & 1307 & $86.2(80.1 ; 92.3)$ & 1215 \\
\hline \multicolumn{7}{|l|}{ Private health plan } \\
\hline No & 1025 & 64.6 & $82.8(80.4 ; 85.2)$ & 8109 & $65.6(62.6 ; 68.7)$ & 6424 \\
\hline Yes & 561 & 35.4 & $78.8(75.3 ; 82.2)$ & 4229 & $61.3(57.1 ; 65.4)$ & 3290 \\
\hline \multicolumn{7}{|l|}{ Medical visit } \\
\hline No & 723 & 45.4 & $73.2(69.8 ; 76.6)$ & 5038 & $54.1(50.3 ; 57.9)$ & 3724 \\
\hline Yes & 868 & 54.6 & $87.9(85.7 ; 90.2)$ & 7276 & $72.1(69.0 ; 75.2)$ & 5968 \\
\hline \multicolumn{7}{|l|}{ Emergency services visit } \\
\hline No & 1387 & 87.2 & $79.4(77.2 ; 81.6)$ & 10496 & $61.4(58.8 ; 64.1)$ & 8117 \\
\hline Yes & 204 & 12.8 & $95.1(92.0 ; 98.2)$ & 1845 & $82.1(76.5 ; 87.6)$ & 1593 \\
\hline \multicolumn{7}{|l|}{ Hospitalization } \\
\hline No & 1310 & 82.3 & $79.9(77.6 ; 82.1)$ & 9969 & $61.3(58.6 ; 64.1)$ & 7648 \\
\hline Yes & 282 & 17.7 & $88.2(84.3 ; 92.2)$ & 2367 & $76.5(71.2 ; 81.7)$ & 2053 \\
\hline \multicolumn{7}{|l|}{ Primary Health Care } \\
\hline Traditional & 741 & 46.5 & $77.9(74.8 ; 81.1)$ & 5491 & $59.7(56.0 ; 63.4)$ & 4208 \\
\hline FHS & 852 & 53.5 & $84.2(81.6 ; 86.7)$ & 6829 & $67.6(64.3 ; 70.8)$ & 5483 \\
\hline Total & 1593 & 100.0 & $81.3(79.3 ; 83.3)$ & 12325 & $64.0(61.5 ; 66.4)$ & 9702 \\
\hline
\end{tabular}

\% prevalence, $\mathrm{Cl}$ confidence interval 
The number of diseases in the same individual ranged from zero to 12 for the 17 problems listed in Table 1 . Only $6.0 \%$ of the total did not have morbidities. Less than $3 \%$ had nine or more morbidities (Fig. 1). Mean morbidity was 3.6 (median =3; Q25 = 2; Q75 = 5).

The percent of participants with multimorbidity was $81.3 \%$ (95 \% CI: 79.3; 83.3) for $\geq 2$ morbidities and $64.0 \%$ (95 \% CI: 61.5; 66.4) for $\geq 3$ morbidities. In both cases occurrence was higher among women, those with black or brown/yellow/indigenous skin, the more elderly, those with less schooling, less purchasing power, the bedridden, those who did not have a health private plan, those having had medical consultations and visited emergency services, those who had been hospitalized and those living in FHS catchment areas (Table 2).

Morbidities showing high prevalence were HBP (55.3\%) and spinal column disease (37.4\%), representing 8383 and 5670 elderly in the target population, respectively. Cancer (4.9\%) and amputation (3.5\%) were the least frequent conditions. Amputation and spinal column disease had been present for a longer length of time. The mean number of diseases ranged from 4.4 (HBP) to 5.8 (urinary incontinence and depression) (Table 3 ).

We found 22 dyads of morbidities with prevalence $\geq 10 \%$ and 35 triads with prevalence $\geq 5 \%$ (Tables 4 and 5). The most prevalent dyads of morbidities were HBP and spinal column disease (23.6\%), and HBP and heart problems $(22.3 \%)$. Four of the dyads did not have frequency statistically higher than expected by chance (Table 4). In the triads, this only occurred with the HBP/ spinal column disease/cognitive impairment triplet (Table 5). In the dyads, the highest ratio between observed and expected frequency was found in rheumatism/arthritis/arthrosis and spinal column disease (O/E: 1.58-95\% CI: 1.43 ; 1.74) (Table 4). Regarding the triads, the highest prevalence found were HBP, rheumatism/arthritis/arthrosis and spinal column disease (10.6), and HBP, heart problem and spinal column disease $(10.4 \%)$. The highest ratio between observed and expected frequency related to triplet rheumatism/arthritis/arthrosis, spinal column disease and urinary incontinence (O/E: 2.53-95 \% CI: 2.06; 3.10) (Table 5).

\section{Discussion}

Multimorbidity frequency was high. At least 4 in every 5 major adults had $\geq 2$ morbidities and 3 in every 5 had $\geq 3$ morbidities, thus confirming the importance of multimorbidity as a frequent problem in older adults. The elevated number of dyads $(n=22)$ with prevalence $\geq 10 \%$ and triads $(n=35)$ with prevalence $\geq 5 \%$ highlights implications for the adequate management of health problems in the same individual, with HBP being the problem most often associated with other morbidities.

The percentage of multimorbidity found is consistent with the range of prevalence encountered in two systematic reviews [25, 26] and recent studies [27, 28]. When considering only population-based studies, the frequency found in our analysis was at least 10 percentage points higher with regard to the occurrence of $\geq 2$ morbidities [25]. The comparability of multimorbidity studies is hampered owing to methodological differences, mainly related to the number of conditions included and the instruments used to measure morbidity.

Achieving standardization is a challenge to the development of knowledge about multimorbidity. References on this topic suggest that only chronic diseases should be included [1]. Despite the importance of acute conditions (e.g. influenza, tonsillitis and pneumonia), which are more susceptible to seasonal variations, their inclusion tends to inflate the occurrence of multimorbidity unnecessarily, thus complicating comparability [1]. Using at least 12 of the most prevalent morbidities appears to be advantageous because they showed lower variability in multimorbidity frequency [25]. Similar to the decision taken in this study, a recent review suggested the inclusion of certain geriatric syndromes in the construct of multimorbidity, such as urinary incontinence and falls [1], considering their relevance for the quality of life and independence of older people and for health care planning.

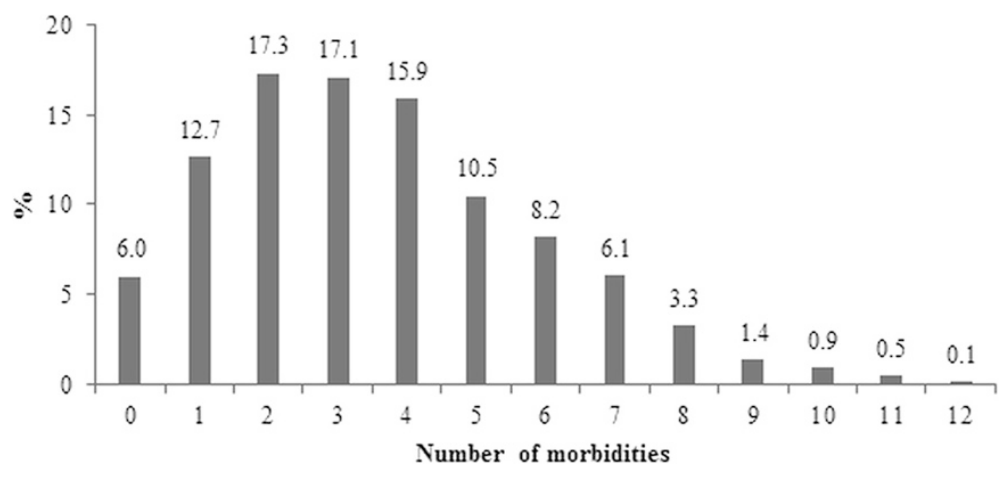

Fig. 1 Prevalence of morbidities by number 
Table 3 Prevalence, cases number in target population, length of time with disease and number of diseases

\begin{tabular}{|c|c|c|c|c|}
\hline \multirow[t]{2}{*}{ Morbidities ( $n$ ) } & \multirow[t]{2}{*}{$\%(95 \% \mathrm{Cl})$} & \multirow{2}{*}{$\begin{array}{l}\text { No. of cases in } \\
\text { target population }\end{array}$} & Time with disease $\mathrm{e}^{\mathrm{a}}$ & \multirow{2}{*}{$\begin{array}{l}\text { Number of diseases } \\
\text { Mean (median; Q25-Q75 }\end{array}$} \\
\hline & & & Mean (median; Q25-Q75) & \\
\hline High Blood Pressure - HBP (1593) & $55.3(52.9-57.8)$ & 8383 & $10.6(8 ; 3-15)$ & $4.4(4 ; 3-6)$ \\
\hline Spinal column disease (1591) & $37.4(35.0-39.8)$ & 5670 & $12.5(10 ; 5-20)$ & $4.7(4 ; 3-6)$ \\
\hline Cognitive impairment (1514) & $34.1(31.7-36.5)$ & 5170 & - & $4.7(4 ; 3-6)$ \\
\hline Heart problem (1593) & $29.6(27.3-31.8)$ & 4487 & $10.4(8 ; 3-15)$ & $5.3(5 ; 4-7)$ \\
\hline Falls (1591) & $28.0(25.8-30.2)$ & 4245 & - & $5.1(5 ; 3-7)$ \\
\hline Eyesight problem (1547) & $27.5(25.3-29.8)$ & 4169 & - & $5.3(5 ; 4-7)$ \\
\hline Rheumatism, arthritis or arthrosis (1592) & $27.3(25.1-29.5)$ & 4139 & $10.9(8 ; 3-15)$ & $5.1(5 ; 4-7)$ \\
\hline Urinary incontinence (1592) & $20.7(18.7-22.7)$ & 3138 & - & $5.8(6 ; 4-7)$ \\
\hline Problem chewing food (1580) & $20.6(18.6-22.6)$ & 3123 & - & $5.3(5 ; 3-7)$ \\
\hline Depression (1512) & $18.0(16.1-19.9)$ & 2729 & - & $5.8(6 ; 4-7)$ \\
\hline Diabetes (1593) & $15.1(13.4-16.9)$ & 2289 & $7.7(5 ;(2-10)$ & $5.2(5 ; 3-7)$ \\
\hline Hearing problem (1550) & $13.4(11.7-15.1)$ & 2031 & - & $5.3(5 ; 4-7)$ \\
\hline Stroke (1593) & $9.9(8.4-11.3)$ & 1501 & $7.8(5 ; 2-10)$ & $5.7(6 ; 4-7)$ \\
\hline Lung problem (1593) & $9.4(7.9-10.8)$ & 1425 & $13.3(6 ; 2-15)$ & $5.4(5 ; 4-7)$ \\
\hline Kidney problem (1591) & $7.2(6.0-8.5)$ & 1092 & $12.1(6 ; 2-15)$ & $5.7(5 ; 4-7)$ \\
\hline Cancer (1591) & $4.9(3.8-6.0)$ & 743 & - & $5.0(5 ; 3-6)$ \\
\hline Amputation (1582) & $3.5(2.6-4.5)$ & 531 & $18.7(14 ; 6-30)$ & $4.8(4 ; 3-6)$ \\
\hline
\end{tabular}

$\%$ prevalence, $\mathrm{Cl}$ confidence interval, Q25-Q75 interquartile range, $n$ sample size ${ }^{a}$ Only for morbidities with medical diagnosis or for amputation

Therefore, taking the 12 most prevalent conditions in our data, multimorbidity frequency was $78.4 \%$ (95 \% CI: 76.4; 80.5) for $\geq 2$ morbidities and $59.5 \%$ (95 \% CI: 57.0; 62.0) for $\geq 3$ morbidities. After excluding urinary incontinence and falls from the morbidities selected in this analysis, the frequencies were $77.1 \%$ (95 \% CI: 75.0; 79.3) for $\geq 2$ and $58.1 \%$ (95 \% CI: 55.6 ; 60.6) for $\geq 3$ morbidities. These findings are slightly lower than those presented in results section. This reflects the low variability in the occurrence of multimorbidity in the sample, regardless of the selected conditions, and confirms the consistency of the prevalence found in this analysis.

The extrapolation of the data and its application to all the elderly living in the city of Bagé intend to subsidize the health policies at SUS, providing an opportunity for municipal health service management to plan actions for elderly people with multimorbidity. This analysis takes into account the percentage of older adults with given characteristics and this contributes to a more detailed evaluation to identify priority groups and the magnitude of impact for future interventions, thus allowing the adequate planning of actions aimed at these individuals. For example, the health care needs will be relatively higher among residents in FHS catchment areas compared to residents in traditional health service catchment areas in the city. Furthermore, the amount of older adults living in FHS are bigger, increasing their relevance for health planning. On the other hand, despite their low proportion, the management of multimorbidity may become more complex in the bedridden elderly compared to those who are not bedridden, eventually calling for more specialized care, and multidisciplinary teams.

Multimorbidity should not be seen as a major limitation of aging since its occurrence is more a rule than an exception. The complications and interactions of multiple chronic diseases represent a major challenge to the health services, because their impact on the autonomy and independence of individuals [17], increasing the risk of disability and frailty $[29,30]$. Complications are related to exacerbation of chronic health problems, for example, uncontrolled high blood pressure that can lead to a stroke and increased risk of disability, or the lack of control of blood glucose levels generating micro and macrovascular problems closely related to the amputation of limbs.

The analysis by demographic, socioeconomic and health service type variables showed the profile of the individuals most affected by multiple problems. Higher occurrence among women may be attributed to survival bias since men tend to die earlier and those who survive are usually the healthiest [4]. Another explanation is related to greater use of medical services by females [31] which was also observed in this study (data not shown) thus enabling more opportunities for medical diagnosis of diseases. This results was similar to previous literature, including populations of others age groups [32, 33]. 
Table 4 Frequent co-occurring dyads ( $\geq 10 \%)$ and observed and expected values

\begin{tabular}{|c|c|c|c|c|}
\hline Frequent co-occurring dyads $(n)$ & Observed (\%) & Expected (\%) & Observed/expected & $95 \% \mathrm{Cl}$ \\
\hline HBP/spinal column disease (1591) & 23.6 & 20.7 & 1.14 & $1.06-1.23$ \\
\hline HBP/heart problem (1593) & 22.3 & 16.4 & 1.37 & $1.26-1.48$ \\
\hline HBP/cognitive impairment (1514) & 19.9 & 18.9 & 1.05 & $0.97-1.15$ \\
\hline HBP/eyesight problem (1547) & 17.1 & 15.2 & 1.13 & $1.03-1.23$ \\
\hline HBP/rheumatism (1592) & 17.0 & 15.1 & 1.13 & $1.03-1.23$ \\
\hline HBP/falls (1591) & 16.8 & 15.5 & 1.09 & $1.00-1.19$ \\
\hline Rheumatism/spinal column disease (1590) & 16.1 & 10.2 & 1.58 & $1.43-1.74$ \\
\hline Heart problem/spinal column disease (1591) & 12.9 & 11.1 & 1.17 & $1.06-1.30$ \\
\hline Spinal column disease/falls (1589) & 12.9 & 10.5 & 1.23 & $1.11-1.37$ \\
\hline HBP/urinary incontinence (1592) & 12.8 & 11.4 & 1.11 & $1.01-1.23$ \\
\hline Spinal column disease/eyesight problem (1545) & 12.4 & 10.3 & 1.20 & $1.08-1.34$ \\
\hline HBP/problem chewing food (1590) & 11.5 & 7.4 & 1.55 & $1.38-1.75$ \\
\hline Heart problem/cognitive impairment (1514) & 11.4 & 10.1 & 1.13 & $1.01-1.26$ \\
\hline Cognitive impairment/falls (1512) & 11.3 & 9.5 & 1.18 & $1.06-1.33$ \\
\hline Cognitive impairment/eyesight problem (1506) & 11.2 & 9.4 & 1.19 & $1.06-1.33$ \\
\hline Spinal column disease/cognitive impairment (1512) & 11.1 & 12.8 & 0.87 & $0.78-0.97$ \\
\hline HBP/depression (1512) & 11.0 & 10.0 & 1.11 & $0.99-1.24$ \\
\hline HBP/diabetes (1593) & 11.0 & 8.4 & 1.32 & $1.17-1.48$ \\
\hline Heart problem/eyesight problem (1547) & 10.7 & 8.1 & 1.32 & $1.17-1.48$ \\
\hline Rheumatism/falls (1590) & 10.4 & 7.6 & 1.37 & $1.21-1.54$ \\
\hline Eyesight problem/falls (1545) & 10.4 & 7.7 & 1.34 & $1.19-1.52$ \\
\hline Rheumatism/cognitive impairment (1513) & 10.1 & 9.3 & 1.09 & $0.97-1.22$ \\
\hline
\end{tabular}

$\%$ prevalence, $\mathrm{Cl}$ confidence interval, $n$ sample size available to analysis

The more elderly who mentioned having black or brown/yellow/indigenous skin color had greater multimorbidity. This finding may be explained by the higher social and economic vulnerability of these individuals in Brazil, highlighting social inequities in health. The higher occurrence of multimorbidity among the more elderly is possibly justified by a greater exposition to physiological stress and, then, to the occurrence of chronic diseases.

The occurrence of multiple health problems was higher among older adults with less schooling and lower income. This finding is similar to the large majority of studies about multimorbidity [27, 33-35], reinforcing the social determination of health and disease. Furthermore, it is worth noting that Brazil is marked by inequalities in access to health services [15] and this could increases severity and complications.

The more elderly who used health services had greater multimorbidity. Reverse causality is marked in these associations because elderly people with more health problems may use more services or the use of services may have increased medical diagnosis. Nevertheless, these associations may reflect the importance of health service utilization as a marker of multiple chronic problems because, for example, almost all $(95.1 \%)$ the elderly who used emergency services had $\geq 2$ health problems. Their relevance as a marker can be an efficient way of quick screening elderly people with multimorbidity during assessments by health professionals. Similarly, the bedridden elderly had more multimorbidity, reflecting the greater vulnerability of these individuals.

The associations with health private plans and the PHC model reflect the focus for actions directed towards management of multimorbidity. Elderly people without private plans and living in FHS catchment areas had more multimorbidity. This confirms social inequities since these elderly were poorer and less educated [21]. Whilst acknowledging that these actions may have been confused by socioeconomic indicators, we believe that an adjusted analysis would not make sense for the purpose of this article. Irrespective of confusion, individuals without a health plan and living in FHS catchment areas have more diseases and greater social and economic vulnerability. Thus, health actions related to the treatment and monitoring of chronic conditions should prioritize these individuals.

The observed/expected ratios were statistically insignificant in four dyads ( $\mathrm{HBP} /$ cognitive impairment; spinal column disease/cognitive impairment; $\mathrm{HBP} /$ depression; 
Table 5 Frequent co-occurring triads ( $\geq 5 \%$ ) and observed and expected values

\begin{tabular}{|c|c|c|c|c|}
\hline Frequent co-occurring triads $(n)$ & Observed (\%) & Expected (\%) & Observed/expected & $95 \% \mathrm{Cl}$ \\
\hline HBP/rheumatism/spinal column disease (1590) & 10.6 & 5.6 & 1.87 & $1.64-2.13$ \\
\hline HBP/heart problem/spinal column disease (1591) & 10.4 & 6.1 & 1.70 & $1.50-1.94$ \\
\hline HBP/heart problem/cognitive impairment (1514) & 8.8 & 5.6 & 1.58 & $1.37-1.81$ \\
\hline HBP/heart problem/eyesight problem (1547) & 8.6 & 4.5 & 1.91 & $1.65-2.21$ \\
\hline HBP/spinal column disease/falls (1589) & 8.6 & 5.8 & 1.48 & $1.29-1.69$ \\
\hline HBP/spinal column disease/cognitive impairment (1512) & 7.7 & 7.1 & 1.10 & $0.96-1.25$ \\
\hline HBP/heart problem/falls (1591) & 7.7 & 4.6 & 1.69 & $1.45-1.96$ \\
\hline HBP/heart problem/rheumatism (1592) & 7.7 & 4.5 & 1.73 & $1.49-2.01$ \\
\hline HBP/rheumatism/falls (1590) & 7.2 & 4.2 & 1.70 & $1.45-1.98$ \\
\hline HBP/cognitive impairment/eyesight problem (1506) & 7.1 & 5.2 & 1.37 & $1.18-1.59$ \\
\hline HBP/rheumatism/cognitive impairment (1513) & 6.8 & 5.1 & 1.33 & $1.14-1.54$ \\
\hline HBP/cognitive impairment/falls (1512) & 6.7 & 5.3 & 1.26 & $1.09-1.47$ \\
\hline HBP/eyesight problem/falls (1545) & 6.5 & 4.3 & 1.52 & $1.29-1.78$ \\
\hline HBP/heart problem/urinary incontinence (1592) & 6.5 & 3.4 & 1.91 & $1.61-2.26$ \\
\hline Rheumatism/spinal column disease/falls (1588) & 6.4 & 2.9 & 2.22 & $1.86-2.66$ \\
\hline HBP/spinal column disease/urinary incontinence (1590) & 6.2 & 4.3 & 1.45 & $1.24-1.70$ \\
\hline HBP/rheumatism/eyesight problem (1546) & 6.0 & 4.2 & 1.45 & $1.23-1.70$ \\
\hline Rheumatism/spinal column disease/eyesight problem (1544) & 6.0 & 3.5 & 1.71 & $1.44-2.03$ \\
\hline HBP/heart problem/problem chewing food (1580) & 5.9 & 3.4 & 1.77 & $1.49-2.10$ \\
\hline HBP/diabetes/heart problem (1593) & 5.9 & 2.5 & 2.39 & $1.97-2.88$ \\
\hline HBP/cognitive impairment/urinary incontinence (1514) & 5.9 & 3.9 & 1.50 & $1.27-1.78$ \\
\hline HBP/cognitive impairment/depression (1502) & 5.7 & 3.4 & 1.69 & $1.42-2.02$ \\
\hline Heart problem/rheumatism/spinal column disease (1590) & 5.7 & 3.0 & 1.87 & $1.57-2.24$ \\
\hline HBP/depression/eyesight problem (1506) & 5.6 & 2.7 & 2.04 & $1.68-2.46$ \\
\hline HBP/urinary incontinence /eyesight problem (1547) & 5.6 & 3.2 & 1.76 & $1.47-2.11$ \\
\hline Heart problem/spinal column disease/eyesight problem (1545) & 5.5 & 3.8 & 1.46 & $1.23-1.73$ \\
\hline HBP/heart problem/depression (1512) & 5.5 & 2.9 & 1.87 & $1.55-2.25$ \\
\hline HBP/rheumatism/urinary incontinence (1591) & 5.5 & 3.1 & 1.75 & $1.46-2.09$ \\
\hline Rheumatism/spinal column disease/urinary incontinence (1589) & 5.3 & 2.1 & 2.53 & $2.06-3.10$ \\
\hline HBP/spinal column disease/problem chewing food (1578) & 5.3 & 4.3 & 1.25 & $1.06-1.47$ \\
\hline HBP/urinary incontinence /falls (1590) & 5.3 & 3.2 & 1.64 & $1.38-1.96$ \\
\hline HBP/eyesight problem/problem chewing food (1547) & 5.2 & 3.1 & 1.67 & $1.39-2.00$ \\
\hline HBP/spinal column disease/depression (1510) & 5.2 & 3.7 & 1.41 & $1.18-1.67$ \\
\hline HBP/depression/falls (1510) & 5.0 & 2.8 & 1.80 & $1.49-2.19$ \\
\hline HBP/cognitive impairment/problem chewing food (1514) & 5.0 & 3.9 & 1.28 & $1.07-1.52$ \\
\hline
\end{tabular}

$\%$ prevalence, $\mathrm{Cl}$ confidence interval, $n$ sample size available to analysis

and rheumatism/cognitive impairment) and one triplet (HBP/spinal column disease/cognitive impairment) with all having depression and cognitive impairment in the combinations. The measurement of these two conditions was done by screening tests, which can increase the false positive and reduce the specificity of combinations with causal relationship, as HBP and cognitive impairment [36]. All the other 18 dyads with prevalence $\geq 10 \%$ and 34 triads with prevalence $\geq 5 \%$ had a greater proportion than expected by chance. This reflects the occurrence of morbidity clusters and a possible causal relationship between morbidities and/or risk factors [37, 38].

However, the observed occurrence alone brings important information for clinical practice and management of the health system and health services in Brazil. For example, approximately one-fifth of the elderly have HBP and spinal column disease, thus indicating that activities for the proper management of a health problem 
should take into account all morbidities and not just one. For example, an elderly person with this pair of diseases should be well instructed on how to engage in physical activities, since although this is widely recognized as a good prognostic factor for HBP, it can also aggravate back problems if undertaken without adequate guidance [39]. The simultaneous occurrence of HBP and cognitive impairment was observed in same proportion as in the previous pair, thus highlighting the need for attention in the approach used in the pharmacological treatment of these elderly people. The same rationale is applicable to disease triads where morbidities and treatment interactions are more important and increase the complexity of health care management.

Worldwide, health systems are still unprepared for the management of individuals with multiple health problems and most guidelines are oriented towards a single disease despite the occurrence of multimorbidity $[12,40]$. The evidence presented here - added to the findings in the international literature $[38,41]$ - contributes to guiding the development and adaptation of Brazilian clinical guidelines.

In order to overcome the challenge of multimorbidity, the current fragmented health care system for the elderly in Brazil should advance to a more comprehensive and multidimensional care [42]. Goals to tackle chronic conditions have recently been established with the publication of the strategic action plan to tackle NCD [14], the discussion on chronic care networks [13] and the consequent approval of the Ministerial Ordinance establishing the SUS Health Care Network for People with Chronic Diseases [43]. However, these guidelines do not adequately include multimorbidity, mainly owing to lack of information on the subject in the Brazil.

Promoting comprehensive care involving a considerable number of diseases, injuries, conditions and complications is a complex task, which requires similarly complex answers. The structure of a health system based on PHC is one of the leading measures to be taken by countries to reduce inequities and improve health care efficiency [44]. In Brazil, these efforts largely depend on FHS universalization and effectiveness.

Some limitations of this study should be addressed. Multimorbidity operationalization did not take into account the severity of the diseases, which could contribute to the identification of priorities in the appropriate management of multiple health problems. However, this approach would require greater detailing of disease severity and for the purpose of this study the use of disease counts is considered more useful than the use of scales/morbidities indices [45]. The other limitation is the absence of information about osteoporosis, thyroid disorders and dyslipidemia and the lack of adequate information necessary to characterize some morbidities.
Although we have adequate measures for chronic morbidities through medical diagnosis (e.g. hypertension and diabetes) and screening for cognitive impairment and depression, we use proxies for other chronic morbidities, such as eyesight, hearing and oral health problems.

Among its strong points, this is a population-based study with low probability of selection bias in virtue of the low number of losses and refusals. Furthermore, the sample characteristics are similar to the Bagé and Brazilian census of elderly population collected in 2000 and 2010. These characteristics strength the internal and external inferences about study, providing support to policy-makers of Bagé and similar Brazilian cities in the actions related to multimorbidity. Moreover, the inclusion of a disease set affecting different body systems (e.g. circulatory, visual and urinary systems) have enabled a more complete approach to evaluate multimorbidity. Finally, reporting the findings in accordance with recommendations in the literature may have contributed to increasing comparability between studies.

\section{Conclusions}

More findings on the prevalence of multimorbidity are needed in order to assess the problem in Brazil, given the scarcity of information. In addition, information about the complications and quality of care for individuals with multimorbidity will be key to ensuring the quality of life for people suffering from different chronic conditions.

Multimorbidity was high in the elderly in Bagé-RS, in keeping with percentages found in other countries. Characteristics of the population with a higher prevalence of multiple chronic problems revealed social inequities that are challenging the health services and health professional training to the adequate management of multimorbidity and its complications in Brazil.

\section{Abbreviations}

ABEP: Associação Brasileira de Empresas de Pesquisas; FHS: Family Health Strategy; HBP: high blood pressure; IBGE: Brazilian Institute of Geography and Statistics; GDS: geriatric depression scale; MMSE: mini-mental state examination; NCD: noncommunicable chronic diseases; SUS: Sistema Único de Saúde (Unified Health System); PHC: primary health care; RS: Rio Grande do Sul state.

\section{Competing interests}

The authors declare that they have no competing interests.

\section{Authors' contributions}

BPN drafted the article and performed the statistical analysis. ET and LAF conceived and designed the study and critically reviewed the manuscript. All authors read and approved the final manuscript.

\section{Acknowledgements}

We are grateful to the Bagé population, including the municipality, the Centro do Idoso, the Universidade da Campanha-URCAMP and the team of interviewers. BPN is supported by Coordination for the Improvement of Higher Level -or Education- Personnel (CAPES). LAF is supported by Brazilian National Research Council (CNPq). The funders had no role in study design, data collection and analysis, decision to publish or preparation of the manuscript. 


\section{Author details}

'Department of Nursing, Federal University of Pelotas, Rua Gomes Carneiro, 1, 96010-610 Pelotas, RS, Brazil. ²Department of Social Medicine, Postgraduate Program of Epidemiology, Federal University of Pelotas, Pelotas, Brazil. ${ }^{3}$ Postgraduate Program of Nursing, Federal University of Pelotas, Pelotas, Brazil.

\section{Received: 11 March 2015 Accepted: 17 November 2015} Published online: 25 November 2015

\section{References}

1. Salive ME. Multimorbidity in older adults. Epidemiol Rev. 2013. doi:10.1093/ epirev/mxs009.

2. Le Reste JY, Nabbe P, Lygidakis C, Doerr C, Lingner H, Czachowski S, et al. A Research Group from the European General Practice Research Network (EGPRN) explores the concept of multimorbidity for further research into long term care. J Am Med Dir Assoc. 2013;14(2):132-3. doi:10.1016/j.jamda. 2012.07.017.

3. Le Reste JY, Nabbe P, Manceau B, Lygidakis C, Doerr C, Lingner $H$, et al. The European general practice research network presents a comprehensive definition of multimorbidity in family medicine and long term care, following a systematic review of relevant literature. J Am Med Dir Assoc. 2013;14(5):319-25. doi:10.1016/j.jamda.2013.01.001.

4. Salomon JA, Wang H, Freeman MK, Vos T, Flaxman AD, Lopez AD, et al. Healthy life expectancy for 187 countries, 1990-2010: a systematic analysis for the Global Burden Disease Study 2010. Lancet. 2012;380(9859):2144-62. doi:10.1016/S0140-6736(12)61690-0.

5. Wang H, Dwyer-Lindgren L, Lofgren KT, Rajaratnam JK, Marcus JR, LevinRector A, et al. Age-specific and sex-specific mortality in 187 countries, 1970-2010: a systematic analysis for the Global Burden of Disease Study 2010. Lancet. 2012;380(9859):2071-94. doi:10.1016/S0140-6736(12)61719-X.

6. Dias da Costa JS, Victora CG. [What's "a public health problem"?]. Rev Bras Epidemiol. 2006:9:144-6. doi:10.1590/S1415-790X2006000100018.

7. Gijsen R, Hoeymans N, Schellevis FG, Ruwaard D, Satariano WA, van den Bos GA. Causes and consequences of comorbidity: a review. J Clin Epidemiol. 2001;54(7):661-74. doi:10.1016/S0895-4356(00)00363-2.

8. Fortin M, Lapointe L, Hudon C, Vanasse A, Ntetu AL, Maltais D. Multimorbidity and quality of life in primary care: a systematic review. Health Qual Life Outcomes. 2004;2:51. doi:10.1186/1477-7525-2-51.

9. de Souza Santos Machado V, Valadares AL, da Costa-Paiva LS, Moraes SS, Pinto-Neto AM. Multimorbidity and associated factors in Brazilian women aged 40 to 65 years: a population-based study. Menopause. 2012;19(5):569-75. doi:10.1097/gme.0b013e3182455963.

10. de Souza Santos Machado V, Valadares AL, Costa-Paiva LH, Osis MJ, Sousa $\mathrm{MH}$, Pinto-Neto AM. Aging, obesity, and multimorbidity in women 50 years or older: a population-based study. Menopause. 2013;20(8):818-24. doi:10. 1097/GME.0b013e31827fdd8c.

11. Andrade LH, Bensenor IM, Viana MC, Andreoni S, Wang YP. Clustering of psychiatric and somatic illnesses in the general population: multimorbidity and socioeconomic correlates. Braz J Med Biol Res. 2010;43(5):483-91. doi:10.1590/S0100-879X2010007500024.

12. Salisbury C. Multimorbidity: redesigning health care for people who use it. Lancet. 2012:380(9836):7-9. doi:10.1016/S0140-6736(12)60482-6.

13. Mendes EV. The care of chronic conditions in primary care: the imperative of strengthening the strategy of family health. Brasilia: Pan American Health Organization; 2012. p. 512.

14. Schmidt MI, Duncan BB, Azevedo e Silva G, Menezes AM, Monteiro CA, Barreto SM, et al. Chronic non-communicable diseases in Brazil: burden and current challenges. Lancet. 2011;377(9781):1949-61. doi:10.1016/s0140-6736(11)60135-9.

15. Paim J, Travassos C, Almeida C, Bahia L, Macinko J. The Brazilian health system: history, advances, and challenges. Lancet. 2011;377(9779):1778-97. doi:10.1016/S0140-6736(11)60054-8.

16. Brazil. PNAB: national primary care policy. Brasilia: Ministry of Health. Secretariat of Health Care. Department of Primary Care; 2012.

17. Moraes EN. Health care for the elderly: conceptual aspects. Brasilia: Pan American Health Organization; 2012. p. 98

18. Malaguarnera M, Vacante M, Frazzetto PM, Motta M. What is the frailty in elderly? Value and significance of the multidimensional assessments. Arch Gerontol Geriatr. 2013;56(1):23-6. doi:10.1016/j.archger.2011.09.017.

19. Veras RP, Caldas CP, Motta LB, Lima KC, Siqueira RC, Rodrigues RTSV. Integration and continuity of Care in health care network models for frail older adults. Rev Saude Publica. 2014;48:357-65. doi:10.1590/S0034-8910. 2014048004941

20. Thume E, Facchini LA, Tomasi E, Vieira LA. Home health care for the elderly: associated factors and characteristics of access and health care. Rev Saude Publica. 2010;44(6):1102-11. doi:10.1590/S0034-89102010005000038.

21. Thumé $E$, Facchini LA, Wyshak G, Campbell P. The utilization of home care by the elderly in Brazil's primary health care system. Am J Public Health. 2011;101(5):868-74. doi:10.2105/ajph.2009.184648.

22. Huntley $A L$, Johnson R, Purdy S, Valderas JM, Salisbury C. Measures of multimorbidity and morbidity burden for use in primary care and community settings: a systematic review and guide. Ann Fam Med. 2012;10(2):134-41. doi:10.1370/afm.1363.

23. Harrison C, Britt $H$, Miller $G$, Henderson J. Examining different measures of multimorbidity, using a large prospective cross-sectional study in Australian general practice. BMJ Open. 2014;4(7). doi:10.1136/bmjopen-2013-004694.

24. Schafer I. Does multimorbidity influence the occurrence rates of chronic conditions? A claims data based comparison of expected and observed prevalence rates. PLoS One. 2012;7(9):e45390. doi:10.1371/journal.pone. 0045390.

25. Fortin M, Stewart M, Poitras ME, Almirall J, Maddocks H. A systematic review of prevalence studies on multimorbidity: toward a more uniform methodology. Ann Fam Med. 2012;10(2):142-51. doi:10.1370/afm.1337.

26. Violan C, Foguet-Boreu Q, Flores-Mateo G, Salisbury C, Blom J, Freitag $M$, et al. Prevalence, determinants and patterns of multimorbidity in primary care: a systematic review of observational studies. PLoS One. 2014;9(7):e102149.

27. Orueta JF, Nuno-Solinis R, Garcia-Alvarez A, Alonso-Moran E. Prevalence of multimorbidity according to the deprivation level among the elderly in the Basque Country. BMC Public Health. 2013;13:918. doi:10.1186/1471-2458-13918.

28. Bahler C, Huber CA, Brungger B, Reich O. Multimorbidity, health care utilization and costs in an elderly community-dwelling population: a claims data based observational study. BMC Health Serv Res. 2015;15(1):23. doi:10. 1186/s12913-015-0698-2.

29. Fried LP, Bandeen-Roche K, Kasper JD, Guralnik JM. Association of comorbidity with disability in older women: the Women's Health and Aging Study. J Clin Epidemiol. 1999;52(1):27-37. doi:10.1016/S0895-4356(98)00124-3.

30. Fried LP, Tangen CM, Walston J, Newman AB, Hirsch C, Gottdiener J, et al. Frailty in older adults: evidence for a phenotype. J Gerontol A Biol Sci Med Sci. 2001;56(3):M146-56. doi:10.1093/gerona/56.3.M146.

31. Mendoza-Sassi R, Béria JU. Health services utilization: a systematic review of related factors. Cad Saude Publica. 2001;17:819-32. doi:10.1590/S0102$311 \times 2001000400016$.

32. Wang HH, Wang JJ, Wong SY, Wong MC, Li FJ, Wang PX, et al. Epidemiology of multimorbidity in China and implications for the healthcare system: cross-sectional survey among 162,464 community household residents in southern China. BMC Med. 2014;12(1):188. doi:10. 1186/s12916-014-0188-0.

33. Barnett K, Mercer SW, Norbury M, Watt G, Wyke S, Guthrie B. Epidemiology of multimorbidity and implications for health care, research, and medical education: a cross-sectional study. Lancet. 2012;380(9836):37-43. doi:10. 1016/s0140-6736(12)60240-2.

34. Jerliu N, Toci E, Burazeri G, Ramadani N, Brand H. Prevalence and socioeconomic correlates of chronic morbidity among elderly people in Kosovo: a population-based survey. BMC Geriatr. 2013;13:22. doi:10.1186/ 1471-2318-13-22.

35. Agborsangaya CB, Lau D, Lahtinen M, Cooke T, Johnson JA. Multimorbidity prevalence and patterns across socioeconomic determinants: a crosssectional survey. BMC Public Health. 2012;12:201. doi:10.1186/1471-245812-201.

36. Qiu C, Winblad B, Fratiglioni $L$. The age-dependent relation of blood pressure to cognitive function and dementia. Lancet Neurol. 2005;4(8):487-99. doi:10.1016/s1474-4422(05)70141-1.

37. Schafer I, Kaduszkiewicz H, Wagner H-O, Schon G, Scherer M, van den Bussche $H$. Reducing complexity: a visualisation of multimorbidity by combining disease clusters and triads. BMC Public Health. 2014;14(1):1285.

38. van den Bussche $H$, Koller D, Kolonko T, Hansen $H$, Wegscheider K, Glaeske $\mathrm{G}$, et al. Which chronic diseases and disease combinations are specific to multimorbidity in the elderly? Results of a claims data based cross-sectional study in Germany. BMC Public Health. 2011;11:101. doi:10.1186/1471-245811-101. 
39. Semlitsch T, Jeitler K, Hemkens LG, Horvath K, Nagele E, Schuermann C, et al. Increasing physical activity for the treatment of hypertension: a systematic review and meta-analysis. Sports Med. 2013;43(10):1009-23. doi:10.1007/s40279-013-0065-6.

40. Guthrie B, Payne K, Alderson P, McMurdo MET, Mercer SW. Adapting clinical guidelines to take account of multimorbidity. BMJ. 2012;345:e6341. doi:10. 1136/bmj.e6341.

41. Sinnige J, Braspenning J, Schellevis F, Stirbu-Wagner I, Westert G, Korevaar J. The Prevalence of Disease Clusters in Older Adults with Multiple Chronic Diseases - A Systematic Literature Review. PLoS One. 2013;8(11):e79641. doi:10.1371/journal.pone.0079641.

42. Muth C, van den Akker M, Blom JW, Mallen CD, Rochon J, Schellevis FG, et al. The Ariadne principles: how to handle multimorbidity in primary care consultations. BMC Med. 2014;12:223. doi:10.1186/s12916-014-0223-1.

43. Brazil. Ordinance No. 252 of 19 February 2013. It establishes the Health Care Network of People with Chronic Diseases in the Unified Health System (SUS). 2013.

44. Atun R, Jaffar S, Nishtar S, Knaul FM, Barreto ML, Nyirenda M, et al. Improving responsiveness of health systems to non-communicable diseases. Lancet. 2013;381(9867):690-7. doi:10.1016/S0140-6736(13)60063-X.

45. Valderas JM, Starfield B, Sibbald B, Salisbury C, Roland M. Defining comorbidity: implications for understanding health and health services. Ann Fam Med. 2009;7(4):357-63. doi:10.1370/afm.983.

46. Lourenço RA, Veras RP. Mini-Mental State Examination: psychometric characteristics in elderly outpatients. Rev Saude Publica. 2006;40:712-9. doi:10.1590/S0034-89102006000500023.

47. Holz AW, Nunes BP, Thume E, Lange C, Facchini LA. Prevalence of cognitive impairment and associated factors among the elderly in Bagé, Rio Grande do Sul, Brazil. Rev Bras Epidemiol. 2013;16:880-8. doi:10.1590/S1415790X2013000400008

48. Sheikh J, Yesavage J. Geriatric Depression Scale (GDS): recent evidence and development of a shorter version. New York: Hayworth; 1986

\section{Submit your next manuscript to BioMed Central and we will help you at every step:}

- We accept pre-submission inquiries

- Our selector tool helps you to find the most relevant journal

- We provide round the clock customer support

- Convenient online submission

- Thorough peer review

- Inclusion in PubMed and all major indexing services

- Maximum visibility for your research 